\title{
Spatial distribution of fine roots on a rehabilitated bauxite residue disposal area in Western Australia
}

\author{
W. Gwenzi Centre for Land Rehabilitation, School of Earth and Environment; and School of Plant Biology, \\ The University of Western Australia, Australia
}

E.J. Veneklaas Centre for Land Rehabilitation, School of Plant Biology, The University of Western Australia, Australia

I. Phillips Alcoa of Australia, Australia

T.M. Bleby School of Plant Biology, The University of Western Australia, Australia

C. Hinz Centre for Land Rehabilitation, School of Earth and Environment, The University of Western Australia, Australia

\begin{abstract}
Root spatial distribution controls water and nutrient uptake, and is a key input in ecohydrological and biogeochemical models. In particular, fine roots are responsible for resource acquisition and represent the most dynamic component of root biomass. While root distribution on natural and agro-ecosystems is relatively well documented, few studies have investigated root spatial distribution on rehabilitated mined ecosystems, where adverse physical and chemical conditions may limit root growth. The authors investigated the spatial distribution of fine roots $(<4.5 \mathrm{~mm}$ diameter) on a rehabilitated bauxite residue disposal area under Mediterranean conditions. The objectives of this study were: to determine the vertical and horizontal spatial variability of fine roots at plot scale; to develop a spatial model for root distribution for use in ecohydrological modelling and other numerical applications; and to compare observed results to those reported in literature for natural ecosystems under similar climatic conditions.

A $20 \times 20 \mathrm{~cm}$ grid sampling scheme was used to collect 226 core samples $(10 \mathrm{~cm}$ diameter and $10 \mathrm{~cm}$ height) from a $700 \mathrm{~cm}$ long and $150 \mathrm{~cm}$ deep trench. Samples were analysed for root length (L), root diameter (D), root length density (RLD) and root biomass density (RBD). Soil dry bulk density, $p H$ and electrical conductivity (EC) were used as indicators of soil physical and chemical constraints to root growth. Root characteristics showed high spatial variability with coefficient of variation (CV) ranging from $51-200 \%$. The top $20 \mathrm{~cm}$ had the highest mean $R L D\left(8.4 \mathrm{~cm} \mathrm{~cm}^{-3}\right)$ and root mass density (RMD) $\left(1 \mathrm{~g} \mathrm{~cm}^{-3}\right)$ which decreased with depth according to a power function $\left(R L D=2474 \times(S D)^{-1.8}, r^{2}=0.92\right)$. About $80 \%$ of the total root length and biomass were in the top $40 \mathrm{~cm}$, while the remainder was in the deeper layers (40$140 \mathrm{~cm})$. At all depths, very fine roots $(\leq 1.5 \mathrm{~mm}$ in diameter) constituted about $95 \%$ of the total root length, suggesting a root system adapted for water uptake in the dry season when soil moisture is limited. Soil EC values were generally low (mean $\left.1.1 \mathrm{dS} \mathrm{m}^{-1}\right)$, but showed high spatial variability $(\mathrm{CV}=91 \%)$ probably due to non-uniform incorporation of chemical amendments. For 19 out of the 24 samples, EC values were below $2.5 \mathrm{dS} \mathrm{m}^{-1}$, considered the upper limit for normal plant growth. Soil pH was slightly alkaline (mean of 8.2), and showed low spatial variability $(C V=4 \%)$. In all cases, bulk densities (mean $=1.3 \mathrm{~g} \mathrm{~cm}^{-3}$ ) were below the critical value for restricted root growth $\left(1.6 \mathrm{~g} \mathrm{~cm}^{-3}\right)$. Correlation analysis suggested that root distribution was not limited by soil dry bulk density, $p H$ and EC. Accordingly, the depth distribution of cumulative RLD and RMD closely agreed $\left(r^{2}=0.93\right)$ with the general root depth distribution models for natural vegetation ecosystems in Mediterranean climates. The results are discussed in the context of vegetation water uptake on rehabilitated mined ecosystems.
\end{abstract}

\section{Introduction}

Engineered cover systems based on the store-release concept are commonly used to restrict water influx into buried hazardous mine wastes. In principle, store-release covers are designed to store infiltrating water in the overlying soil layers, and slowly release it back to the atmosphere as evapotranspiration. Whilst empirical 
data is still limited, the role of vegetation and its feedbacks on water balance fluxes is widely recognised (Scanlon et al., 2005). The capacity of vegetation to control deep drainage through root water uptake depends on root distribution, rooting depth, root density and root size distribution. Fine roots are the most dynamic component of belowground biomass and are responsible for resource uptake, and carbon and nutrient cycling. Accordingly, root data are key inputs in ecohydrological and biogeochemical models used to simulate water and biomass partitioning (Jackson et al., 1996). Whilst root distribution in natural and agroecosystems is well documented (Jackson et al., 1996; Liedgens and Richner, 2001), such data is still limited for rehabilitated mine sites.

Compared to natural and agro-ecosystems, rehabilitated mine sites represent unique and highly diverse ecosystems, which may exhibit adverse chemical conditions such as extreme soil $\mathrm{pH}$, chemical toxicities and high salinity. Moreover, mining operations and material handling during subsequent rehabilitation can modify the physical properties, resulting in high penetration resistance and bulk densities (Arunachalam et al., 2004; Mengler et al., 2006). Dry bulk density and penetration resistance are commonly used as indices of soil compaction or mechanical restriction to root growth. Due to ease and speed of measurement, dry bulk density is one of the most frequently used parameters to measure soil compaction (Thompson et al., 1987). Penetration resistance has been criticised for its high sensitivity to antecedent soil moisture content. Moreover, dry bulk density correlates well with, and is inversely proportional to root growth (Thompson et al., 1987). A value of $1.6 \mathrm{~g} \mathrm{~cm}^{-3}$ is often cited as a critical dry bulk density beyond which plant root growth is restricted. A field study on coarse root architecture on rehabilitated bauxite mine sites in Western Australia have shown that cemented lateritic subsoil restricted root growth (Szota et al., 2007). A comparative study of Banksia root architecture on rehabilitated sand quarries and natural woodlands showed that higher penetration resistance and bulk densities exceeding critical values of $2 \mathrm{MPa}$ and $1.6 \mathrm{~kg} \mathrm{~m}^{-3}$, respectively, restricted root growth on reconstructed soils (Rokich et al., 2001). Similar findings have been reported on rehabilitated gold mines in Western Australia (Arunachalam et al., 2004). Besides the few studies highlighted, root spatial distribution on rehabilitated mine sites, and the extent to which physical and chemical properties influence the distribution are relatively unknown. Moreover, most studies to date focused on coarse root architecture and qualitative root distribution, but ignored fine roots and their spatial distribution.

Root spatial distribution determines the ability of vegetation to access water and nutrients essential for growth and survival. Numerous models have been proposed for root depth distribution. Among the most prominent are; steady or steep decrease from top to bottom layers; an increase in the top layers down to a depth of maximum root growth, followed by a decrease in soil layers below; and an irregular or random distribution with depth (Liedgens and Richner, 2001). The patterns have been shown to be influenced by vegetation species, age and soil environmental conditions (Schenk, 2008). The distributions have often been described by mathematical functions. Amongst the prominent ones is a non-linear single parameter model originally developed by Gale and Grigal (1987), and fitted to a global root database by Jackson et al. (1996):

$$
Y=1-\beta^{d}
$$

where:

$Y=$ the cumulative root fraction at any soil depth.

$d \quad=\quad(\mathrm{cm})$ from the surface.

$\beta=\quad$ a root extinction parameter. High values of $\beta(\approx 0.97)$ correspond to greater proportion of roots at deeper soil depths, while low values $(\approx 0.92)$ imply greater root proportion near the soil surface.

Besides vertical root distribution, variability in the horizontal direction may also influence root water uptake and consequently water redistribution. Compared to depth distribution, literature on horizontal distribution of fine roots is very limited. Root studies in field crops have often observed two horizontal patterns; decreasing root density at increasing distances from the plant rows; and a uniform distribution at increasing distances from plants (Liedgens and Richner, 2001). In the Mojave Desert, Wilcox et al. (2004) showed that horizontal fine root distribution differed among four shrub species depending on root foraging strategies. For example Ambrosia dumosa and Ephedra nevadensis had significantly more active fine roots in the canopy than intercanopy, while Larrea tridentata showed the opposite trend. Lycium pallidum showed similar fine root 
length between canopy and intercanopy. A study on fine root distribution in blue oak trees concluded that distance from individual trees had no significant effect on fine root distribution (Millikin and Bledsoe, 1999).

We investigated the spatial distribution of fine roots in a mixed stand of woody tree and shrub species on a rehabilitated bauxite residue disposal area in Western Australia. We hypothesised that fine roots will be concentrated in the canopy spaces close to individual plants, and decline gradually as distance increases, reaching a minimum in the intercanopy spaces. Using soil $\mathrm{pH}, \mathrm{EC}$ and soil dry bulk density as indicators of soil chemical and physical constraints to root growth, we further hypothesised that root distribution were constrained by, and negatively correlated to these soil properties. The objectives of this study were:

- To determine the vertical and horizontal spatial distribution of fine roots at stand scale.

- To develop a spatial model for root distribution for use in ecohydrological modelling and other numerical applications.

- To compare observed root depth distribution to the global Jackson model.

\section{$2 \quad$ Materials and methods}

\subsection{Description of study site}

The study was conducted at a rehabilitated bauxite residue disposal area (RDA) in Kwinana, about $35 \mathrm{~km}$ southwest of Perth, Western Australia. The site experiences a Mediterranean-type climate characterised by cool wet winter (mean annual rainfall: $700 \mathrm{~mm}$ ) and hot to warm dry summer seasons. The RDA is a disposal facility for residue rock wastes from a bauxite refinery plant. The residue is separated into alkaline mud $(<150 \mu \mathrm{m}$ in diameter, $\mathrm{pH} \approx 12)$ and sandy fraction $(>150 \mu \mathrm{m}$ in diameter). As part of the rehabilitation programme, the mud is discharged into tailings dams, whose embankments are constructed at about six per cent slope using the residue sand. The 6-10 $\mathrm{m}$ thick sandy layer is characterised by very high saturated hydraulic conductivity $\left(>100 \mathrm{~cm} \mathrm{hr}^{-1}\right)$ and low available water holding capacity. After incorporating $2.25 \mathrm{t}$ gypsum ha ${ }^{-1}$ and $2.75 \mathrm{tha}^{-1}$ of diammonium-based fertiliser, vegetation was established from seedlings and seed. Vegetation at the study site consisted of a mixed stand dominated by woody species Acacia rostillifera, Melaleucas nesophila, Acacia saligna and other species endemic to coastal dune ecosystems of Western Australia. The study plot was established in 2004 and had an average stem density of $188 \pm 50.7$ plants ha $^{-1}$ at the time of the study.

\subsection{Sampling strategy}

Sampling was conducted in the dry season in November 2008. A reconnaissance survey was conducted at the study site to map the spatial distribution of vegetation. The RDA showed sparse vegetation distribution dominated by trees, shrubs, and bare intercanopy patches. A ten metre long transect, representative of the general spatial distribution of vegetation was located along the slope. The objective was to capture fine root distribution in the canopy and intercanopy bare patches. A mini-backhoe was used to excavate a trench ( $7 \mathrm{~m}$ long and $1.5 \mathrm{~m}$ deep) along the transect, making a vertical profile on one wall of the trench, which was used for sampling. Cylindrical metal cores $\left(100 \mathrm{~cm}^{2}\right)$ were used for soil sampling. A $20 \times 20 \mathrm{~cm}$ grid sampling design was used to collect samples to a depth of $140 \mathrm{~cm}$.

\subsection{Laboratory analysis}

In the laboratory, samples were sieved through a stack of three sieves $(2,1$ and $0.4 \mathrm{~mm}$ diameter) arranged in descending order. For each sample, roots retained on each sieve were pooled together for further analysis. Since the focus was at ecosystem scale, roots were not separated by species or life forms. Debris, dead roots and soil particles were removed and roots cleaned using deionised water. For each sampling depth, ten samples were selected at random for scanning and image analysis. Roots were scanned using a flat bed scanner set at 300 dpi photo image. Images were analysed using WinRhizo image analysis software (Regent Instruments, Quebec, Canada). Roots were oven dried at $60^{\circ} \mathrm{C}$ for 24 hours and weighed to determine root dry biomass (RDB). L to RDB linear relationships were used to estimate L for unscanned samples. Root mass and length densities were computed as: 


$$
\begin{gathered}
R M D=\frac{R D B}{V} \\
R L D=\frac{L}{V}
\end{gathered}
$$

where:

$$
\begin{array}{lll}
R M D & = & \text { root mass density }\left(\mathrm{g} \mathrm{cm}^{-3}\right) . \\
R L D & = & \text { root length density }\left(\mathrm{cm} \mathrm{cm}^{-3}\right) . \\
V & = & \text { the volume of the core }\left(\mathrm{cm}^{3}\right) .
\end{array}
$$

\subsection{Soil dry bulk density, $\mathrm{pH}$ and electrical conductivity}

Soil $\mathrm{pH}$ and EC were used as indicators of soil chemical conditions. Similarly, dry bulk density was used as an indicator of soil mechanical resistance to root growth. Dry bulk density, unlike penetration resistance used in other studies, is not affected by antecedent soil moisture. The core method (Blake and Hartge, 1986) was used to measure soil dry bulk density. After separating roots, core samples were oven dried at $102^{\circ} \mathrm{C}$ for 24 hours, and used to compute dry bulk density $\left(\rho_{b}\right)$ as follows:

$$
\rho_{b}=\frac{M_{s}}{V_{t}}
$$

where:

$$
\begin{array}{lll}
M_{s} & = & \text { oven dry mass of soil }(\mathrm{kg}) . \\
V_{t} & = & \text { total volume of soil core }\left(\mathrm{m}^{3}\right) .
\end{array}
$$

To investigate the relationship between root spatial distribution and soil $\mathrm{pH}$ and $\mathrm{EC}$, biased soil samples representing high $\left(>1.0 \mathrm{~g} \mathrm{~cm}^{-3}\right)$, moderate $\left(0.5-1.0 \mathrm{~g} \mathrm{~cm}^{-3}\right)$ and low $\left(<0.5 \mathrm{~g} \mathrm{~cm}^{-3}\right)$ root biomass were selected from the sample pool. Soil $\mathrm{pH}$ and electrical conductivity were measured on sieved soil $(<2 \mathrm{~mm})$ using standard methods (Rayment and Higginson, 1992).

\subsection{Statistical analysis}

Summary statistics (mean, coefficient of variation) were computed for RMD and RLD. Data were subjected to one way ANOVA using depth and horizontal distance as factors. Regression analysis was used to determine the effects of soil properties on root distribution. SAS statistical program (SAS Institute Inc., Cary, $\mathrm{NC}, \mathrm{USA}$ ) was used for statistical analysis.

\section{$3 \quad$ Results and discussion}

\subsection{Root diameter distribution}

Fine roots considered in this study ranged from $0.5-4.5 \mathrm{~mm}$ in diameter. Root size distribution was highly skewed towards very fine roots $(<1.5 \mathrm{~mm}$ diameter). About $95 \%$ of RLD and RMD were less than $1.5 \mathrm{~mm}$ in diameter while about $80 \%$ were less than $0.5 \mathrm{~mm}$ in diameter (Figure 1).

Comparison with other studies is limited by lack of literature on fine root distribution on rehabilitated mine sites. However, similar trends have been reported (Millikin and Bledsoe, 1999) on root distribution in natural vegetation although the proportions vary among studies. For example, the observed values were comparable to $71 \%$ reported by Millikin and Bledsoe (1999) for blue oak. Contrary to what has been reported for some vegetation types (Hendrick and Pregitzer, 1996), depth had no effect on root size distribution. The high proportion of fine roots relative to other size fractions may be a vegetation adaptation strategy meant to enhance water uptake. 


\subsection{Root distribution with depth}

Mean root depth distribution showed high spatial variability as indicated by the high coefficient of variation (50-200\%). Since RLD and RMD were correlated only RLD data are shown. Fine roots in the $0-40 \mathrm{~cm}$ surface soil layer represented approximately $80 \%$ of the total RMD and RLD (Figure 2).

Mean root densities significantly $(\mathrm{p}<0.05)$ decreased with increasing soil depth $(S D)$ according to power function (Equation (5)). This trend is often observed in natural and agro-ecosystems (Kage, 1997; Jackson et al., 1996; Schenk, 2008).

$$
R L D=2474(S D)^{-1.8}, \quad r^{2}=0.92
$$

Differences in sampling depths, methods and units of measurement, and inconsistencies in what root diameters constitute fine roots make direct comparison with other studies on natural and agricultural systems difficult. However, the trend of higher root densities in the upper soil layers shown by our data is broadly consistent with the literature (Laclau et al., 2001; Schenk, 2008; Jackson et al., 1996), particularly studies that show greater root growth in surface soil layers in nutrient poor soils and in regions characterised by infrequent pulse rainfall events (Schenk, 2008). This rooting pattern may allow for efficient uptake of water and nutrients from surface soil layers which are often characterised by relatively higher nutrients than underlying layers.

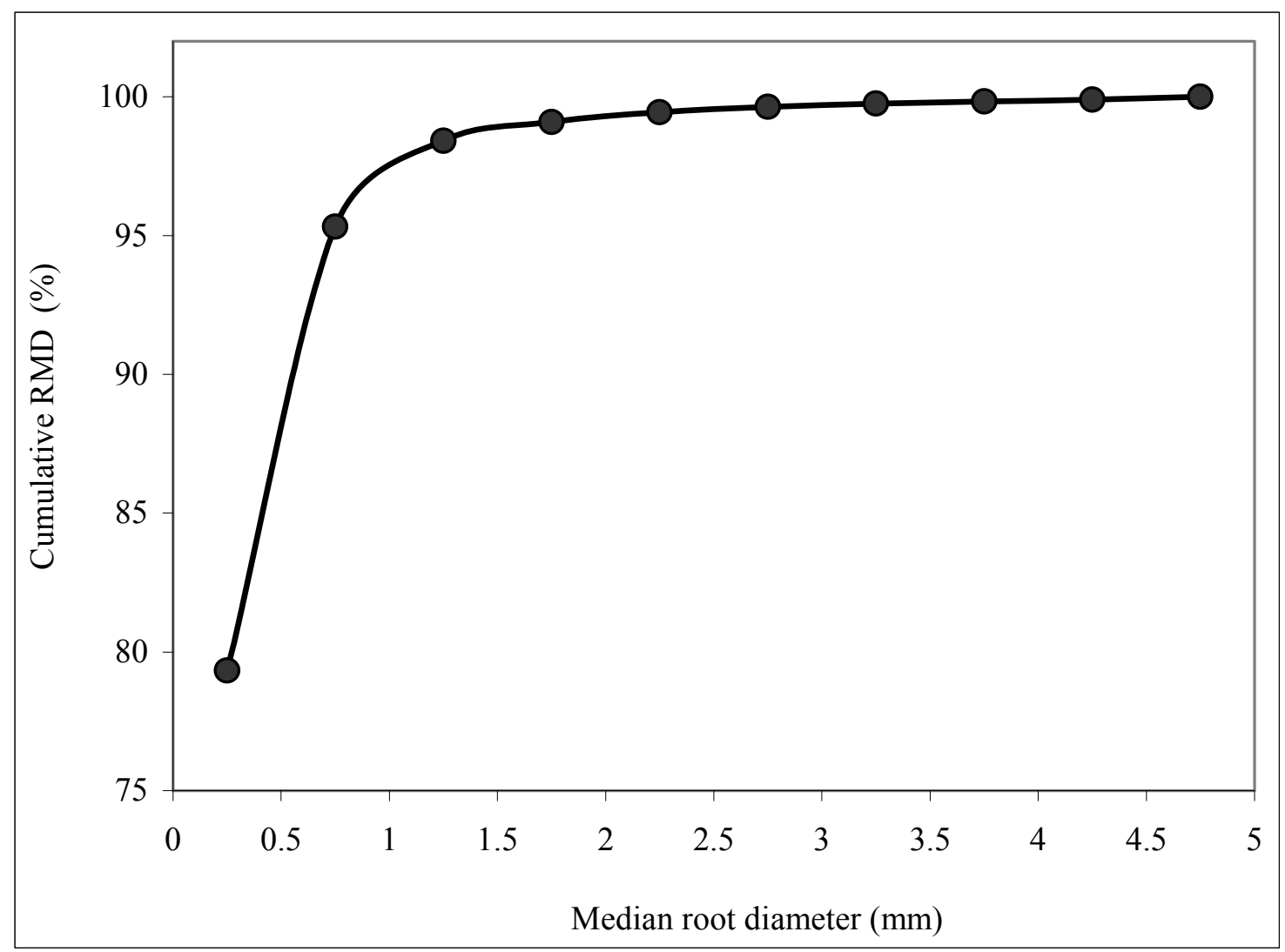

Figure 1 Cumulative (RMD) in each root diameter class. Root diameters indicated are median values 


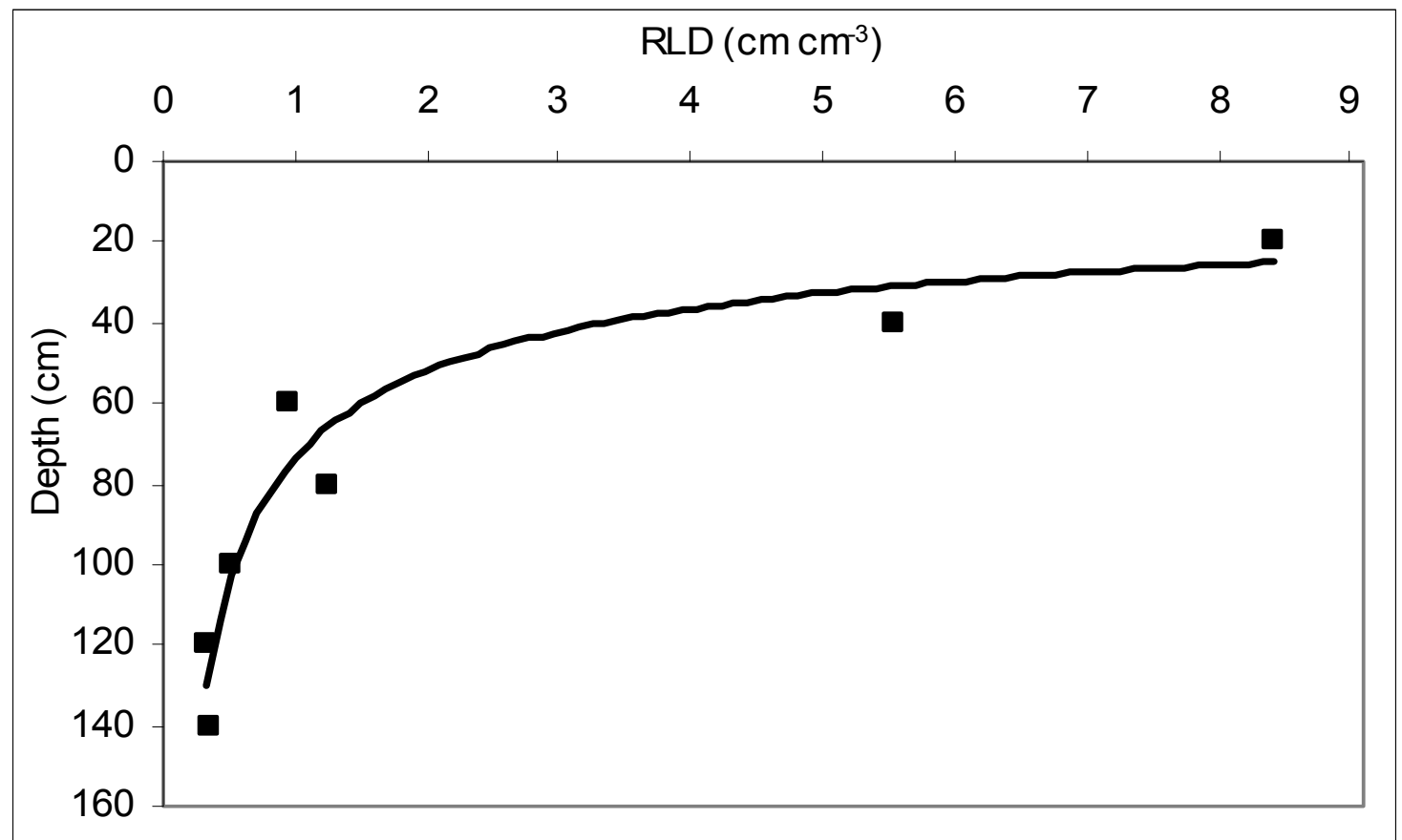

\section{Figure 2 Depth distribution of mean fine RLD}

To investigate whether root depth distribution deviates significantly from that expected in natural ecosystems, observed root depth distribution patterns were compared to the Jackson model. Considering that the model is based on a large database consisting of 250 studies, we considered it as representative of general root distribution in natural terrestrial biomes. In the context of this study, we focus on cumulative root depth distribution for sclerophyll shrubs and trees. Such ecosystems are closest natural analogues of the temperate vegetation common in Western Australia. The Jackson model considers cumulative normalised root depth distribution using root extinction parameter $(\beta)$ values of 0.964 for sclerophyll shrubs and trees and 0.966 for temperate deciduous forests.

Figure 3 compares measured cumulative root distribution to that estimated by the Jackson model. Our results showed a good agreement $\left(r^{2}=0.9\right)$ between modelled and measured data, suggesting that the general root depth distribution is within the trends expected for natural Mediterranean vegetation ecosystems. However, for the parameter values given in Jackson et al. (1996), measured values were slightly lower than model estimates, particularly in the top $80 \mathrm{~cm}$ depth. This discrepancy could be due to the fact that the model is based on mean data from numerous field studies, and that actual root biomass in each soil layer may vary among sites.

It is noteworthy that root depth distribution may also depend on stand age, although this is not always the case. Investigating root spatial distribution in one to nine year old eucalyptus stands in the Congo, Bouillet et al. (2002) concluded that age had no effect on maximum rooting depth, but significantly increased root density in the surface layers. Tree roots quickly developed an extensive root system reaching beyond three metres deep and up to the middle of the inter-row. 


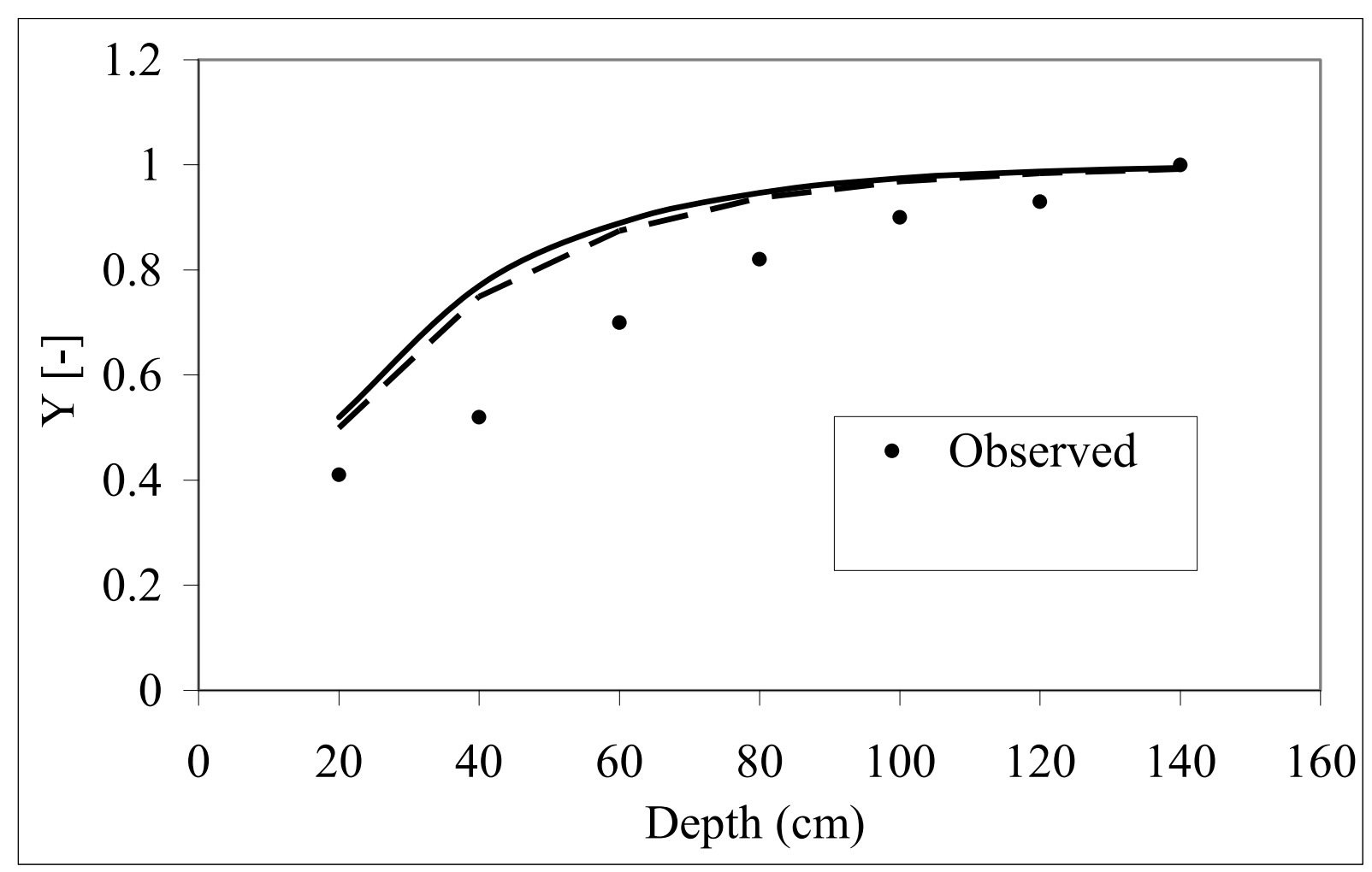

Figure 3 Depth distribution of observed and modelled cumulative root mass density fraction (Y). The Jackson model corresponds to the cumulative root depth distribution for sclerophyll shrubs $(\beta=0.964)$ and temperate deciduous forest $(\beta=0.966)$ according to the global Jackson model

\subsection{Root horizontal distribution}

Root distribution varied significantly $(\mathrm{P}<0.05)$ in the horizontal direction, but highest root density was not always associated with spatial location of individual plants (Figure 4). In general, fine root distribution showed a more complex horizontal pattern than in the vertical direction. Horizontal root distribution was characterised by a sinusoidal or wavy behaviour (Figure 4). The wavy pattern was quite prominent in the top $80 \mathrm{~cm}$ depth, but appears muted at lower depths. Contrary to our hypothesis and literature on fine root distribution in field crops (Liedgens and Richner, 2001), maximum root density did not always coincide with the location of individual plants. Whilst this pattern has not been reported in literature, Wilcox et al. (2004) observed that some shrub species in the Mojave Desert, USA, had a tendency to concentrate fine roots in the intercanopy spaces. Our observations suggest that species have root systems extending far beyond their canopies, forming a network of overlapping root systems in the intercanopy spaces. Further evidence of this rooting pattern is provided by preliminary excavation of individual species at the site, which showed that some keystone species had lateral roots extending to approximately $4.2 \mathrm{~m}$ from the main stem. 


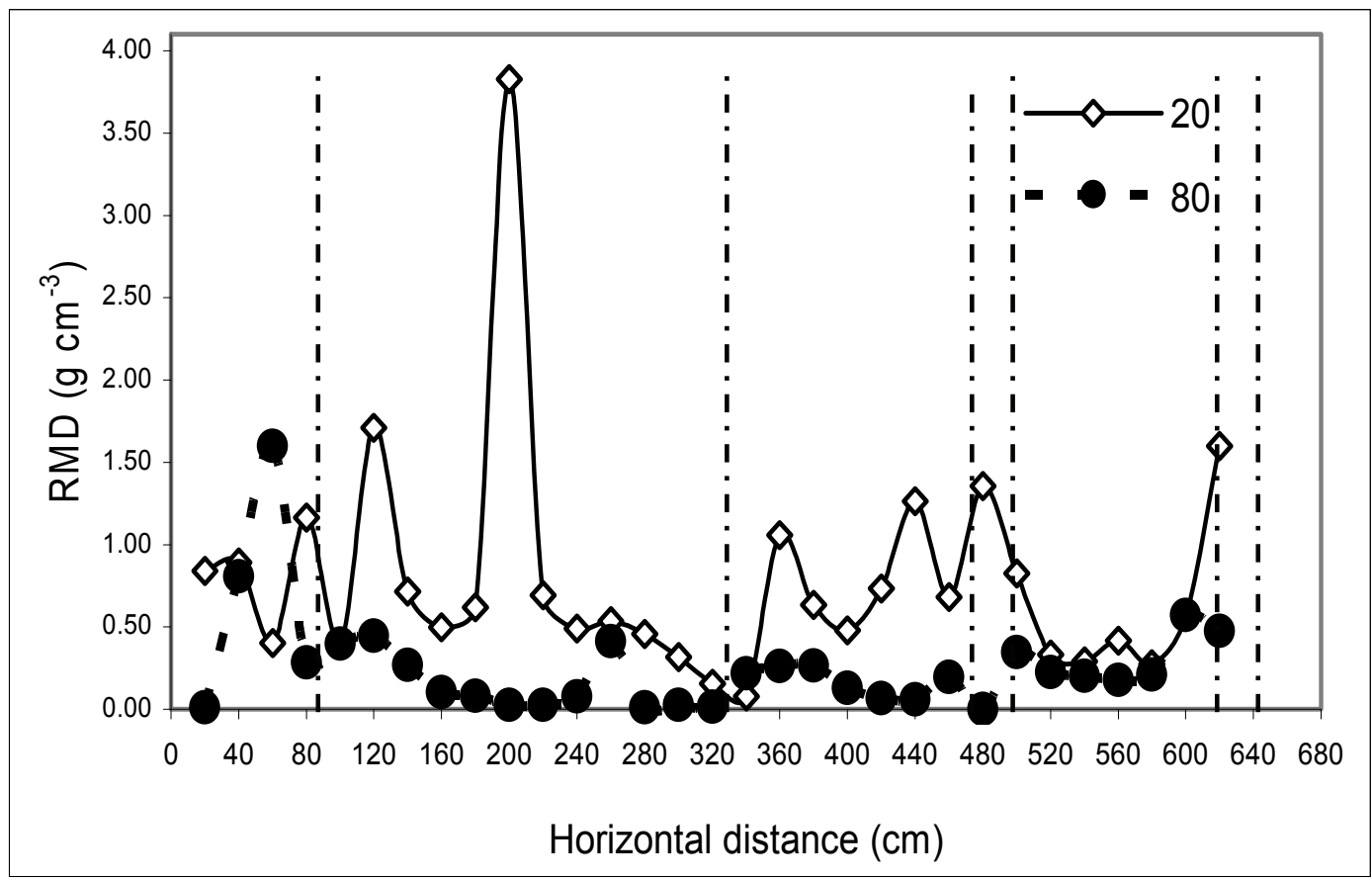

Figure 4 Horizontal root mass density (RMD) distribution for the 0-20 and 60-80 $\mathrm{cm}$ depths. Dotted lines indicate location of individual plants along the transect

Given the relationship between fine root density and resource uptake (Kage, 1997), similar spatial patterns are expected for root water uptake at plot scale. Consequently, preferential deep drainage is expected in patches with relatively low root density particularly during the wet season. To overcome this problem, increasing root density through artificial vegetation regeneration has been suggested as a strategy to reduce deep drainage (Liedgens and Richner, 2001). In this case, the complex spatial pattern observed makes it difficult to identify these zones from aboveground vegetation distribution. However, due to difficulties in quantifying the amount of root density required to reduce deep drainage to a minimum level, the data presented should be considered in relative terms.

\subsection{Relationship between root distribution and soil properties}

Soil properties are often considered one of the key controls of root spatial distribution. In particular, extreme soil $\mathrm{pH}$, salinity and high bulk densities are often associated with reconstructed profiles on rehabilitated mine sites (Rokich et al., 2001; Mengler et al., 2006). Soil pH, EC and dry bulk density showed no distinct depth and horizontal trends. Dry bulk density values were low (mean: $1.3 \mathrm{~g} \mathrm{~cm}^{-3}$ ) and within expected ranges for sandy soils. Field observation during sampling showed no evidence of compaction throughout the profile. Observed dry bulk density values were below the critical value for restricted root growth $\left(1.6 \mathrm{~g} \mathrm{~cm}^{-3}\right)$ reported by Rokich et al. (2001). However, dry bulk density values were lower than those reported in previous studies conducted on rehabilitated bauxite mines in Western Australia, where high bulk densities exceeding the limit values were observed (Szota et al., 2007; Rokich et al., 2001). For example, Rokich et al. (2001) reported that high bulk densities exceeding $1.6 \mathrm{~g} \mathrm{~cm}^{-3}$ restricted root growth on soils reconstructed from bauxite residues. This disparity could be attributed to site-specific material handling and construction procedures.

Besides mechanical impedance, soil $\mathrm{pH}$ and EC may inhibit root growth and function by reducing soil osmotic potential and creating specific ion toxicities (Jacobs and Timmer, 2005). Soil pH was slightly alkaline (mean of 8.2$)$ with very low variability $(\mathrm{CV}=4 \%)$. The $\mathrm{pH}$ range (7.6-8.9) was within expected ranges for gypsum amended bauxite residues. Courtney and Timpson (2005) observed similar $\mathrm{pH}$ values (8.0) for gypsum amended bauxite residue in Ireland. They reported that gypsum application at three per cent w/w lowered $\mathrm{pH}$ from 9.5 to 8.0, although the processes involved remain unclear. Soil EC values ranged from $0.18-2.99 \mathrm{dS} \mathrm{m}^{-1}$ with a mean of $1.09 \mathrm{dS} \mathrm{m}^{-1}$. Variability for $\mathrm{EC}$ was high $(\mathrm{CV}=91 \%)$ probably due to 
non-uniform incorporation of chemical amendments such as fertilisers and gypsum. There has been an unconfirmed notion that root growth on rehabilitated bauxite mine sites is limited by the depth of gypsum incorporation, which is thought to reduce soil alkalinity. Although there was field evidence of non-uniform incorporation of gypsum, our data shows that this had no effect on soil $\mathrm{pH}$ and root distribution. Consequently, low root biomass at lower depths cannot be explained by high soil $\mathrm{pH}$. Instead, a decline in root biomass with depth is common even in natural systems (Jackson et al., 1996). It is noteworthy that there are no clearly defined $\mathrm{pH}$ and EC limit values for natural tree and shrub species, where root response may depend on species and developmental stage. While most agricultural crops can tolerate EC values up to $4.0 \mathrm{dS} \mathrm{m}^{-1}$, woody and forest species are considered sensitive to values as low as $1.4 \mathrm{dS} \mathrm{m}^{-1}$ (Jacobs and Timmer, 2005). In most instances, $2.5 \mathrm{dS} \mathrm{m}^{-1}$ is often considered the threshold EC value (Jacobs and Timmer, 2005). Out of the 20 samples analysed, 19 had EC values lower than the limits for normal root growth. Even in cases where the limits were exceeded, there was no evidence of EC effects on root distribution. Overall, observed root spatial distribution could not be explained by measured soil $\mathrm{pH}$, EC and dry bulk density. This observation could suggest that material handling, construction procedures and incorporation of chemical amendments such as gypsum were successful in creating conducive soil conditions for root growth. In addition, belowground species interactions and other soil properties which were not investigated in this study could probably explain the observed root spatial distribution. The fact that our results contradict the general belief that rehabilitated mine sites exhibit adverse chemical and physical conditions for root growth emphasises the need for site-specific studies to understand factors limiting root growth and vegetation establishment.

\subsection{Implications for cover systems}

Fine root distribution showed high spatial variability in both vertical and horizontal directions. Despite this variability, clear vertical and horizontal spatial patterns emerged from the data. Whilst root vertical distribution showed a gradual decline with depth, complex spatial patterns were observed in the horizontal direction. The peaks of sinusoidal curves did not always coincide with spatial location of plants. In the context of cover systems, the observed vertical and horizontal distribution of fine roots will have important hydrological implications for cover systems. Fine root density and distribution is often correlated with root water uptake, and consequently deep drainage and nutrient leaching. Considering that fine roots are concentrated in the top $0-40 \mathrm{~cm}$ depth of the profile, the probability of root water uptake will decline proportionally with depth. Consequently, once water moves beyond the top $40 \mathrm{~cm}$, the risk of deep drainage is high. High saturated hydraulic conductivity and low water holding capacity are likely to enhance the downward movement of water. Horizontal fine root distribution was characterised by a series of peaks and troughs, indicating that fine roots exist as clusters interspersed with zones of low root density. These zones of low root density represent hydrological 'hotspots' characterised by rapid deep drainage during rainfall events. Moreover, studies have shown that at plot scale, root water uptake is higher under uniformly distributed than clustered root systems (Liedgens and Richner, 2001). That peak fine root density did not always coincide with location of individual plants showed that roots extended beyond plant canopy. In addition, the high spatial variability evident in the data means that the mean is not the best estimate of root density distribution. Therefore, attempts to use mean root data to quantify ecohydrological and biogeochemical fluxes through modelling at spatial levels higher than point scale entail substantial uncertainties. However, the nature of horizontal variation observed presents a challenge for any targeted artificial regeneration of vegetation. It is unclear whether artificial vegetation regeneration in the intercanopy bare patches will improve uniformity of root density distribution or enhance the risk of root competition for resources.

\section{$4 \quad$ Summary and conclusions}

We investigated fine root spatial distribution on a rehabilitated bauxite mine site in Western Australia and tested the influence of depth, aboveground distribution of plants and soil properties on root distribution. Overall, very fine roots ( $>1.5 \mathrm{~mm}$ in diameter) dominated the fine root component, which plays a key role in water and nutrient uptake. The bulk of the roots were in the top $40 \mathrm{~cm}$ of the profile, and decreased gradually with depth, reaching a maximum rooting depth of about $150 \mathrm{~cm}$. Root mass and length densities were equal or higher than those reported for natural and agro-ecosystems. In addition, root depth distribution and maximum rooting depth closely agreed with estimates from root models for terrestrial biomes. This suggests 
that belowground ecosystem productivity at the study site is comparable to that of their natural counterparts. Root spatial distribution varied by similar magnitude in both vertical and horizontal directions. Mean root depth distribution followed a simple power function which agreed closely with the Jackson model. On the other hand, root horizontal distribution exhibited a complex sinusoidal pattern which did not always coincide with aboveground plant distribution. This observation conflicts the notion that fine roots are concentrated close to individual plants, and decrease towards the intercanopy patches. The trend indicates that roots from individual plants had a large lateral extent and possibly overlapped. However, the distribution was independent of soil $\mathrm{pH}, \mathrm{EC}$ and dry bulk density which were generally within acceptable ranges for normal root growth. Whilst most previous studies have focussed on vertical distribution, our data showed that variation in the horizontal scale was equally important and of similar magnitude. Considering that root density is related to water uptake, our results have important hydrological implications on cover systems. Given the high root spatial variability, root water uptake and hence deep drainage are expected to be characterised by high vertical and horizontal anisotropy. In addition, our data suggests ecohydrological and biogeochemical models relying on one dimensional mean root parameters to simulate root and nutrient uptake at higher spatial scales are prone to large uncertainties. Capturing the observed variability would require sophisticated sampling designs that may be labour-intensive and time-consuming. We are furthering this work by investigating the seasonal dynamics of fine roots in response to environmental factors.

\section{Acknowledgements}

The authors are grateful to the ACMER Cover project and mining companies for funding, Alcoa of Australia staff for logistical support and Johannes Albers for field and laboratory assistance. Willis Gwenzi thanks The University of Western Australia for scholarship support.

\section{References}

Arunachalam, S.K., Hinz, C. and Aylmore, G. (2004) Soil physical properties affecting root growth in rehabilitated gold mine tailings, SuperSoil 2004, 3rd Australian New Zealand Soils Conference, 5-9 December 2004, University of Sydney, Australia, pp. 1-7.

Blake, G.R. and Hartge, K.H. (1986) Bulk density, In Methods of Soil Analysis Part 1, A. Klute (ed), ASA Monograph, No. 9, 2nd edition, Madison, Wisconsin, USA, pp. 363-376.

Bouillet, J.P., Laclau, J.P., Arnaud, M., M'Bou, A.T., Saint-André, L. and Jourdan, C. (2002) Changes with age in the spatial distribution of roots of Eucalyptus clone in Congo, impact on water and nutrient uptake, for Ecol Manage, Vol. 171, pp. 43-57.

Courtney, R.G. and Timpson, J.P. (2005) Reclamation of fine fraction bauxite processing residue (red mud) amended with coarse fraction residue and gypsum, Water, Air, and Soil Pollution, Vol. 164, pp. 91-102.

Gale, M.R. and Grigal, D.K. (1987) Vertical root distributions of northern tree species in relation to successional status, Canadian Journal of Forest Research, Vol. 17, pp. 829-834.

Hendrick, R.L. and Pregitzer, K.S. (1996) Temporal and depth related patterns of the fine root dynamics in northern hardwood forests, Journal of Ecology, Vol. 84, pp. 167-176.

Jackson, R.B., Canadell, J., Ehleringer, J.R., Mooney, H.A., Sala, O.E. and Schulze, E.D. (1996) A global analysis of root distributions for terrestrial biomes, Oecologia, Vol. 108, pp. 389-411.

Jacobs, D.F. and Timmer, V.R. (2005) Fertilizer-induced changes in rhizosphere electrical conductivity: relation to forest tree seedling root system growth and function, New Forests, Vol. 30, pp. 147-166.

Kage, H. (1997) Is low rooting density of faba beans a cause of high residual nitrate content of soil at harvest? Plant and Soil, Vol. 190, pp. 47-60.

Laclau, J.P., Arnaud, M., Bouillet, J.P. and Ranger, J. (2001) Spatial distribution of Eucalyptus roots in a deep sandy soil in the Congo: relationships with the ability of the stand to take up water and nutrients, Tree Physiology, Vol. 21, pp. 129-136.

Liedgens, M. and Richner, W. (2001) Minirhizotron observations of the spatial distribution of the maize root system, Agronomy Journal, Vol. 93, pp. 1097-1104.

Mengler, F.C., Kew, G.A., Gilkes, R.J. and Koch, J.M. (2006) Using instrumented bulldozers to map spatial variation in the strength of regolith for bauxite mine floor rehabilitation, Soil and Tillage Research, Vol. 90, pp. 126-144.

Millikin, C.S. and Bledsoe, C.S. (1999) Biomass and distribution of fine and coarse roots from blue oak (Quercusdouglasii) trees in the northern Sierra Nevada foothills of California, Plant and Soil, Vol. 214, pp. $27-38$.

Rayment, G.E. and Higginson, F.R. (1992) Australian laboratory handbook of soil and water chemical methods, Inkata Press, Melbourne, 330 pp. 
Rokich, D.P., Meney, K.A., Dixon, K.W. and Sivasithamparam, K. (2001) The impact of soil disturbance on root development in woodland communities in Western Australia, Australian Journal of Botany, Vol. 49, pp. 169-183.

Scanlon, B.R., Levitt, D.G., Keese, K.E., Reedy, R.C. and Sully, M.J. (2005) Ecological controls on water-cycle response to climate variability in deserts, In Proceedings of the National Academy of Science, Vol. 102(17), pp. 6033-6038.

Schenk, H.J. (2008) The shallowest possible water extraction profile: A null model for global root distribution, Vadose Zone Journal, Vol. 7, pp. 1119-1124.

Szota, C., Veneklaas, E.J., Koch, J.M. and Lambers, H. (2007) Root Architecture of Jarrah (Eucalyptus marginata) Trees in Relation to Post-Mining Deep Ripping in Western Australia, Restoration Ecology, Vol. 15(14) (Supplement), pp. S65-S73.

Thompson, P.J., Jansen, I.J. and Hooks, C.L. (1987) Density as parameters for predicting root system performance in mine soils, Soil Science Society of America Journal, Vol. 51, pp. 1288-1293.

Wilcox, C.S., Ferguson, J.W., Fernandez, G.C.J. and Nowak, R.S. (2004) Fine root growth dynamics of four Mojave Desert shrubs as related to soil moisture and microsite, Journal of Arid Environments, Vol. 56, pp. 129-148. 